\title{
Treatment of Methicillin-Resistant Staphylococcus aureus: Vancomycin and Beyond
}

\author{
Natasha E. Holmes, MBBS, FRACP, PhD ${ }^{1}$ Steven Y. C. Tong, MBBS, FRACP, PhD ${ }^{2}$ \\ Joshua S. Davis, MBBS, FRACP, PhD ${ }^{2,3}$ Sebastiaan J. van Hal, MBChB, FRACP, FRCPA, PhD ${ }^{4,5}$
}

1 Department of Infectious Diseases, Austin Centre for Infection Research, Heidelberg, Victoria, Australia

2 Department of Global and Tropical Health, Menzies School of Health

Address for correspondence Sebastiaan J. van Hal, MBChB, FRACP, FRCPA, PhD, Royal Prince Alfred Hospital, Missenden Road,

Research, Darwin, Northern Territory, Australia

Camperdown, New South Wales 2050, Australia (e-mail: Sebastian. vanhal@sswahs.nsw.gov.au).

${ }^{3}$ Department of Infectious Diseases, John Hunter Hospital, Newcastle, New South Wales, Australia

${ }^{4}$ Department of Microbiology and Infectious Diseases, Royal Prince

Alfred Hospital, Sydney, Australia

${ }^{5}$ University of Western Sydney, Sydney, Australia

Semin Respir Crit Care Med 2015;36:17-30.

\begin{abstract}
Keywords

- methicillin-resistant Staphylococcus aureus

- vancomycin

- individualized dosing

- daptomycin

- linezolid

- lipoglycopeptides

- $\beta$-lactams

There has been a welcome increase in the number of agents available for the treatment of methicillin-resistant Staphylococcus aureus (MRSA). Vancomycin remains an acceptable treatment option, with moves toward individualized dosing to a pharmacokinetic/ pharmacodynamic (PK/PD) target. Numerous practicalities, however, would need to be resolved before implementation. Lipoglycopeptides as a class show excellent in vitro potency. Their long half-lives and complex PKs may preclude these agents being used in critically ill patients. Anti-MRSA cephalosporins provide great promise in the treatment of MRSA. These agents, despite broad-spectrum activity, should be reserved for patients with MRSA infections as it is likely that usage will be associated with increased rates of resistance. Daptomycin is currently the only antibiotic to have shown noninferiority to vancomycin in the treatment of MRSA bacteremia. The results of an open-labeled trial to address the superiority of daptomycin compared with vancomycin in reduced vancomycin susceptibility infections are eagerly anticipated. No drug to date has shown superiority to vancomycin in the treatment of MRSA infections with the possible exception of linezolid in hospital-acquired pneumonia (HAP), making linezolid an important option in the treatment of MRSA-proven HAP. Whether these strengths and features are agent or class specific are unclear but will likely be answered with the marketing of tedizolid. There are insufficient data to recommend either quinupristin/ dalfopristin or tigecycline, as first line in the treatment of severe MRSA infections. These agents however remain options in patients with no other alternatives.
\end{abstract}

Staphylococcus aureus is a gram-positive bacterium that remains a troublesome pathogen especially within the hospital setting. This bacterium forms a part of the normal human nasal microflora and may cause infections in susceptible individuals especially in health care settings. What makes this bacterium a problem is its propensity to spread, especially in health care settings, and its remarkable capacity to evolve new antibiotic resistance. Not surprisingly therefore, S. aureus has been identified as one of the key "problem" bacteria in addition to Enterococcus faecium, Klebsiella
Issue Theme Antimicrobial Resistance: Management of Superbugs; Guest Editor, David L. Paterson, MBBS, PhD, FRACP, FRCPA
Copyright (c) 2015 by Thieme Medical Publishers, Inc., 333 Seventh Avenue, New York, NY 10001, USA. Tel: +1(212) 584-4662.
Dol http://dx.doi.org/ 10.1055/s-0034-1397040. ISSN 1069-3424. 
pneumoniae, Acinetobacter baumannii, Pseudomonas aeruginosa, and Enterobacter species; these are the ESKAPE pathogens that urgently require development of new therapies. ${ }^{1}$

The overall burden of antimicrobial-resistant bacteria continues to increase and accounted for approximately $20 \%$ of all hospital infections in $2010 .^{2}$ These infections in turn are associated with increased patient morbidity and mortality. ${ }^{3}$

The rates of methicillin-resistant $S$. aureus (MRSA) are dynamic with current United States and European surveillance data suggesting that MRSA incidence has declined by between 27.7 and $54.2 \%$ in recent years. ${ }^{4}$ Although these MRSA figures are encouraging, the impact of emerging community MRSA clones on health care-related infections is yet to become clear; regardless, MRSA infections are likely to continue to be a significant problem.

The purpose of this review is to explore the possible treatment options available for MRSA including new data related to vancomycin optimization. We will focus on initial therapy and not discuss issues surrounding either maintenance options, which generally following an extended period of parenteral therapy and usually consist of an oral agent, combination treatment or salvage therapy.

\section{Vancomycin Optimization}

Vancomycin was introduced in 1958 initially for the treatment of penicillin-resistant $S$. aureus but was quickly superseded by methicillin. Vancomycin rose to prominence following the emergence of MRSA and has been the mainstay of treatment for MRSA ever since. It is a glycopeptide with activity against gram-positive pathogens through inhibition of cell wall synthesis. ${ }^{5,6}$ Although, vancomycin has been used for over 50 years, multiple controversies still exist about the optimum usage of this agent.

\section{Pharmacokinetic/Pharmacodynamic Considerations}

The pharmacokinetic/pharmacodynamic (PK/PD) parameter that best predicts vancomycin efficacy is the ratio of the area under the 24-hour concentration curve (AUC) to the minimum inhibitory concentration (MIC) of the infecting organism (AUC/MIC).$^{7-9}$ Moise et al investigated the utility of AUC/ MIC in predicting the clinical and microbiological success of vancomycin treatment in a single-center study of 62 patients with S. aureus pneumonia (the majority of whom had ventilator-associated pneumonia [VAP]). ${ }^{10}$ Using classification and regression tree analysis, vancomycin AUC/MICs of greater than 345 and 866 were associated with clinical and microbiological success, respectively. On the basis of these data, and a subsequent validation study by the same authors in $S$. aureus pneumonia, ${ }^{11}$ a vancomycin AUC/MIC of $\geq 400$ has been recommended in consensus guidelines to predict successful therapy. ${ }^{9}$

Individualizing the vancomycin exposure-response relationship by dosing vancomycin to attain this PK/PD target may improve clinical outcomes. However, clinicians should be aware of the inherent variability that exists between methods used to obtain either AUC or MIC values and the expertise required to implement such a practice.
AUC Measurements and Therapeutic Drug Monitoring There are several methods that can be employed to obtain the $\mathrm{AUC}^{12}$; and include determination based on multiple sampling in a dosing interval; calculations based on PK data (trough levels); Bayesian modelling and AUC calculations using a simple formula based on daily vancomycin dose and creatinine clearance (Eq. [1]). In most cases the Cockcroft-Gault equation is used as a measure of creatinine clearance. The most accurate (i.e., the closest to the true AUC value), remains actual AUC measurements followed by Bayesian methods using population data and formula-based methods. ${ }^{13}$

Currently, the most feasible and practical method for AUC determination remains using a surrogate measure, serum trough concentrations, despite poor accuracy when compared with the above methods. ${ }^{13}$ Trough levels between 15 and $20 \mu \mathrm{g} / \mathrm{mL}$ are recommended based on the original modelling data and correspond with attaining a AUC/MIC target $>400$ provided that the MIC of the organism is $\leq 1 \mu \mathrm{g} /$ $\mathrm{mL} .9,14,15$ Conversely, the probability of target attainment is less likely in high vancomycin MIC infections and this has been the main rationale for alternative antimicrobial therapy in these situations. ${ }^{16,17}$

Consensus guidelines recommend serum trough concentrations be taken at steady state, ${ }^{9}$ and it is important to realize that the timing of sample collection (a trough level, i.e., before the next dose) is vital to maintain accuracy of vancomycin dose adjustments. ${ }^{18}$

\section{Dosing Considerations}

Vancomycin is usually administered through intermittent dosing. Due to the importance of achieving therapeutic vancomycin serum concentrations early in the course of infection, a loading dose of vancomycin have been proposed especially in seriously ill patients. ${ }^{9,19-21}$ Continuous infusions have also been proposed as faster achievement of target concentrations and less variability in serum concentrations and AUC have been observed with continuous infusions. ${ }^{22,23}$ Although no improved clinical outcomes have yet been reported with such a strategy, continuous infusion have been associated with lower rates of nephrotoxicity and a higher steady state concentration, with the nephrotoxicity threshold around $28 \mu \mathrm{g} / \mathrm{mL}$ compared with intermittent infusions. ${ }^{24,25}$

\section{Minimum Inhibitory Concentration Determinations}

The denominator of the PK/PD equation, the MIC result, varies between methodologies, ${ }^{26,27}$ which in turn have a significant impact on the final ratio. ${ }^{28}$ Few diagnostic laboratories routinely perform the reference broth microdilution (BMD) method for MIC determination and instead use a gradient diffusion method such as Etest (bioMérieux, Inc., Durham, NC) that is less expensive and less labor-intensive. Similarly, automated antibiotic susceptibility platform results differ from BMD and Etest and as such clinicians need to take into account MIC methodology in AUC/MIC target determination. ${ }^{29}$

\section{The Optimal AUC Target}

Several clinical studies have evaluated the vancomycin AUC/MIC target associated with outcome. The vancomycin 
AUC/MIC target varies among these studies, secondary to the variability in AUC calculation, MIC methodology, clinical $S$. aureus infection syndrome, and outcomes measured (-Table 1). Reassuringly, observed targets tend to be similar between studies and comparable to the original and recommended AUC/MIC target (i.e., > 400) when employing similar methodology. It is important to note, however, that these studies have all examined vancomycin AUC within the first 96 hours and currently there are no randomized controlled studies that examine whether adjustment of vancomycin dosing regimens prospectively during a treatment course to achieve specific target AUC/MIC ratios are associated with improved clinical outcomes.

Eq. (1) shows the formula for area under the 24-hour concentration curve (AUC):

$$
\mathrm{AUC}_{24}=\frac{\mathrm{D}}{([\mathrm{CLCr} \times 0.79)+15.4] \times 0.06}
$$

where $\mathrm{D}$, total vancomycin dose in 24 hours; CLCr, creatinine clearance calculated by various methods.

\section{Ongoing and Unresolved Controversies}

The current vancomycin MIC susceptibility breakpoint is $2 \mu \mathrm{g} / \mathrm{mL}^{37}$ Debate exists whether the current breakpoint needs to be lowered, as infections caused by isolates with an elevated or high vancomycin MIC (at the upper end of the susceptible range; $\leq 2 \mu \mathrm{g} / \mathrm{mL}$ ) are associated with worse clinical outcomes. ${ }^{38}$ In addition, as discussed above, PK/PD target attainment is unlikely with current vancomycin dosing for these infections. ${ }^{17}$ Controversy exists however, as outcomes with these infections may not reflect antibiotic failure per se but may rather be a marker for some other pathogen or host characteristic. This is best illustrated by two studies that observed a similar association with high vancomycin MIC and outcomes in methicillin-sensitive $S$. aureus (MSSA) infections treated with flucloxacillin. ${ }^{39,40}$ Similarly, certain strains known as heterogeneous vancomycin-intermediate $S$. aureus (hVISA); which contain a subpopulation of VISA, are associated with comparable clinical outcomes to vancomycin susceptible $S$. aureus infections, ${ }^{41-43}$ despite having elevated MICs (predominantly around $2 \mu \mathrm{g} / \mathrm{mL}$ ) in routine laboratory testing. Possible explanations include the reduced virulence ${ }^{44}$ and lower rates of shock ${ }^{45}$ observed with hVISA. Considering all the above data, and that no new antimicrobial agents had demonstrated superiority over vancomycin in clinical trials, the Infectious Diseases Society of America MRSA treatment guidelines at the time of publication recommended vancomycin as first-line therapy regardless of the vancomycin MIC and switching to alternative therapy if there is documented

Table 1 Comparison of vancomycin AUC/MIC calculations and impact on clinical outcomes in Staphylococcus aureus infection

\begin{tabular}{|c|c|c|c|c|}
\hline $\begin{array}{l}\text { Publication } \\
\text { year/reference }\end{array}$ & No. & Clinical syndrome & Outcome & $\begin{array}{l}\text { MIC methodology and observed } \\
\text { AUC/MIC target }\end{array}$ \\
\hline \multicolumn{5}{|c|}{ Formula-based ${ }^{a}$ AUC determination using Cockcroft-Gault equation to estimate renal function } \\
\hline $2000^{10}$ & 62 & MSSA and MRSA pneumonia & Treatment success & $\begin{array}{l}\text { BMD }>345 \text { clinical } \\
\text { BMD }>866 \text { microbiological }\end{array}$ \\
\hline $2004^{11}$ & 90 & MSSA and MRSA pneumonia & Treatment success & $\begin{array}{l}\text { BMD }>350 \text { clinical } \\
\text { BMD } \geq 400 \text { microbiological }\end{array}$ \\
\hline $2010^{30}$ & 222 & MSSA and MRSA bacteremia & Persistent bacteremia & No target detected \\
\hline $2013^{28}$ & 182 & MSSA and MRSA bacteremia & Mortality & $\mathrm{BMD}<373$ \\
\hline $2014^{31}$ & 127 & MRSA bacteremia & Treatment failure & $\begin{array}{l}\text { BMD }<398 \\
\text { Etest }<270\end{array}$ \\
\hline \multicolumn{5}{|c|}{ Formula-based ${ }^{a}$ AUC determination using population-based vancomycin clearances } \\
\hline $2011^{32}$ & 320 & MRSA bacteremia & Treatment failure & Etest $<421$ \\
\hline $2013^{33}$ & 35 & $\begin{array}{l}\text { MRSA bacteremia with septic } \\
\text { shock }\end{array}$ & In-hospital mortality & $\mathrm{BMD}<451$ \\
\hline \multicolumn{5}{|c|}{ Formula-based $^{\mathrm{a}}$ AUC determination using pharmacokinetic data and Bayesian modelling } \\
\hline $2012^{34}$ & 50 & $\begin{array}{l}\text { Complicated MRSA bacteremia } \\
\text { and endocarditis }\end{array}$ & Attributable mortality & Etest $<211$ \\
\hline $2013^{35}$ & 59 & MRSA bacteremia osteomyelitis & Bacterial clearance & BMD $>293$ \\
\hline $2014^{36}$ & 76 & MRSA infections & Treatment failure & $\begin{array}{l}\text { BMD }<430 \\
\text { Etest }<399\end{array}$ \\
\hline $2014^{13}$ & 123 & MRSA bacteremia & Treatment failure & $\begin{array}{l}\text { BMD }<521 \\
\text { Etest }<303\end{array}$ \\
\hline
\end{tabular}

Abbreviations: AUC, area under the 24-hour concentration curve; BMD, broth microdilution; MIC, minimum inhibitory concentration; MRSA, methicillin-resistant Staphylococcus aureus; MSSA, methicillin-sensitive Staphylococcus aureus.

Note: Etest (bioMérieux, Inc., Durham, NC).

${ }^{a}$ See Eq. (1) for the formula. 
clinical or microbiologic failure. ${ }^{16}$ For isolates with an MIC $>2 \mu \mathrm{g} / \mathrm{mL}$ there is no role for vancomycin and an alternative agent should be administered.

Despite these complexities and controversies, vancomycin is likely to remain an option for the treatment of MRSA. However, dose optimization by way of individualized dosing toward a PK/PD target will probably be recommended in the future, albeit in selected patient groups where antibiotic therapy significantly impacts outcomes (e.g., critically ill).

\section{Teicoplanin}

Teicoplanin is a glycopeptide with a similar mode of action to vancomycin. Much debate has surrounded this antibiotic, however, due to data showing inferior efficacy compared with vancomycin. ${ }^{46}$ These results can be explained by inadequate dosing of teicoplanin secondary to greater protein binding compared with vancomycin. ${ }^{47}$ Recent data and a meta-analysis both conclude that teicoplanin (at higher and appropriate dosing) is not inferior to vancomycin, ${ }^{48,49}$ and may be associated with a lower rate of adverse events. ${ }^{48}$ Higher teicoplanin MICs have also been associated with poor clinical outcomes and increased mortality in teicoplanin-treated patients with MRSA bacteremia and pneumonia, ${ }^{50,51}$ mirroring the phenomenon observed with high vancomycin MIC infection. Teicoplanin is not currently available in the United States.

\section{Lipoglycopeptides}

Oritavancin, telavancin, and dalbavancin are semisynthetic lipopolypeptide analogues of vancomycin with activity against MRSA. In common with vancomycin, they each contain a heptapeptide core that enables inhibition of cell wall synthesis. Each agent also contains a lipophilic side chain that prolongs their half-life and increases their activity against gram-positive cocci by greater binding to peptidoglycan precursors to prevent cell wall synthesis. Oritavancin and telavancin also disrupt membrane barrier function of S. aureus. ${ }^{52-54}$ All three drugs have activity against MRSA and VISA, oritavancin, ${ }^{55}$ dalbavancin, ${ }^{56}$ and telavancin ${ }^{57}$ have activity against vancomycin-resistant S. aureus (VRSA).

\section{Telavancin}

The lipophilic side chain of telavancin confers enhanced potency, with approximately 10 -fold more potency than vancomycin. It has in vitro activity against MRSA, VISA, daptomycin nonsusceptible and linezolid nonsusceptible S. aureus. ${ }^{53,58,59}$ In vitro studies of hVISA clinical strains suggest that telavancin has superior bactericidal activity compared with vancomycin and linezolid. ${ }^{60}$

Telavancin was approved in November 2009 in the United States for the treatment of acute bacterial skin and skin structure infections (ABSSSI), however the marketing application for this indication in Europe was withdrawn in October 2008 due to concerns in the review process such as lack of additional benefit over vancomycin, potential increased nephrotoxicity compared with vancomycin, possible increased QT prolongation, and possible impurities in the production process. ${ }^{61}$ It was granted marketing approval in May 2011 in Europe and in June 2013 in the United States (with a black box warning) for hospital-acquired pneumonia (HAP) caused by gram-positive pathogens including MRSA where alternative treatments are not suitable based on the results of the ATTAIN studies. ${ }^{62}$ Of note, comparable cure rates were noted in patients with MRSA HAP $(81.8 \%$ for telavancin vs. $74.1 \%$ for vancomycin). A posthoc analysis of these studies demonstrated comparable 28-day overall survival rates between the two groups; however lower survival was observed in telavancin-treated patients with moderate-to-severe renal insufficiency (creatinine clearance $<50 \mathrm{~mL} / \mathrm{min}$ and $<30 \mathrm{~mL} / \mathrm{min}$, respectively), consequently the black box warning in the United States. ${ }^{63}$

A randomized phase two clinical trial (the ASSURE study) was recently published evaluating intravenous telavancin $10 \mathrm{mg} / \mathrm{kg}$ once daily compared with comparators (intravenous vancomycin $1 \mathrm{~g}$ twice daily or intravenous antistaphylococcal penicillin $2 \mathrm{~g} 6$ hourly) for the treatment of uncomplicated $S$. aureus bacteremia (SAB). ${ }^{64}$ Similar cure rates were seen between both groups at a test-ofcure visit scheduled at 84 days after commencement of study medication. Although drug discontinuation rates were similar in both treatment arms, adverse events were more frequent with telavancin, notably clinically significant elevations in serum creatinine. ${ }^{64}$ Although MRSA bacteremia accounted for almost half of the patients enrolled in this study (15/31) only nine patients were in the clinically evaluable population precluding any treatment recommendations at this stage.

QT prolongation is a recognized adverse event of telavancin, with the risk reported to be similar to fluoroquinolones. $^{64-66}$ To date, no cardiovascular events attributed to QT prolongation have been reported. Transient elevations in serum creatinine and thrombocytopenia have also been observed. ${ }^{62,66}$

\section{Dalbavancin}

Dalbavancin is a lipoglycopeptide derived from teicoplanin. It has a prolonged terminal half-life up to 250 hours, which allows once weekly dosing. ${ }^{58,67,68}$ Compared with vancomycin and daptomycin, it has 8- to 16-fold more activity against MRSA, hVISA, and VISA with typical MICs ranges between $\leq 0.03$ and $0.12 \mu \mathrm{g} / \mathrm{mL}$ for MSSA and MRSA ${ }^{69,70}$ Clinical trials have been performed in ABSSSI but not invasive infections. DISCOVER 1 and 2 were studies comparing intravenous dalbavancin $1 \mathrm{~g}$ on day 1 followed by $500 \mathrm{mg}$ on day 8 with intravenous vancomycin $1 \mathrm{~g}$ or $15 \mathrm{mg} / \mathrm{kg}$ twice daily (for a minimum of 3 days) plus a step-down to oral linezolid $600 \mathrm{mg}$ twice-daily to complete 10 to 14 days of treatment. ${ }^{71}$ To obtain possible registration by the U.S. Food and Drug Administration (FDA), these studies were required to utilize stricter enrolment criteria, which included larger areas of erythema or greater complexity with abscess formation, and were required to measure clinical response at 48 to 72 hours. ${ }^{72}$ Consequently, unlike previous skin and soft tissue trials, patients enrolled in the DISCOVER studies were more likely to be systemically unwell (more than $85 \%$ with fever, $50 \%$ had the systemic inflammatory response syndrome) with a greater burden of infection (the area of erythema was $\sim 4$ - 
fold the FDA requirement). Overall, dalbavancin was noninferior to the comparator arm, including the subset of patients with MRSA with few observed adverse effects mainly comprising gastrointestinal upset and pruritus. ${ }^{71}$ Based on these data, dalbavancin received FDA approval for ABSSSI in the United States in May 2014, and it is currently under review in Europe.

\section{Oritavancin}

Oritavancin is a lipoglycopeptide derived from vancomycin and is rapidly bactericidal with extensive tissue distribution. ${ }^{73,74}$ Not surprisingly, preclinical studies suggest highly variable dosing strategies between 200 and 1,200 mg. ${ }^{58}$ Like dalbavancin it has a prolonged half-life up to 393 hours. The comparable potency of oritavancin is less clear as previous MICs results are inaccurate, as the drug has been found to stick to plastic tubes and microdilution wells, affecting the final MIC result. This phenomenon can be overcome by the addition of $0.002 \%$ polysorbate $80 .^{75}$ Regardless of these in vitro issues, oritavancin retains activity against hVISA, VISA, and VRSA strains. ${ }^{76,77}$ In addition, it has activity against mecC MRSA, ${ }^{78}$ and remains highly effective against multidrug resistant $S$. aureus clinical isolates. ${ }^{76,79}$

Like dalbavancin, there are no clinical studies in invasive infection and there are no clinical trials registered with ClinicalTrials.gov for the treatment of bacteremia or endocarditis. SOLO 1 and 2 were multicenter randomized double-blind studies evaluating a single dose of intravenous oritavancin $1,200 \mathrm{mg}$ compared with intravenous vancomycin $1 \mathrm{~g}$ or $15 \mathrm{mg} / \mathrm{kg}$ twice daily for the treatment of ABSSSI thought or proven to be caused by a gram-positive pathogen. Results from SOLO 1 were recently published showing noninferiority of oritavancin compared with vancomycin for the primary composite endpoint of early clinical evaluation at 48 to 72 hours, including the subset of patients with MRSA-proven ABSSSI. ${ }^{80}$ Despite concerns about QT prolongation similar to telavancin, there were no significant differences in electrocardiogram findings with adverse effects and rates of discontinuation similar between the two treatment groups. This study also recruited patients using the new stricter FDA criteria, and patients in SOLO 1 were sicker than those in DISCOVER 1 and $2 .{ }^{81}$ Oritavancin was recently granted regulatory approval in August 2014 in the United States, and it is currently under priority review in Europe.

\section{Anti-MRSA Cephalosporins}

In the treatment of MSSA infections, $\beta$-lactams are associated with improved clinical outcomes when compared with vancomycin or glycopeptides. ${ }^{82-86}$ These data are so compelling that guidelines state that vancomycin should be avoided in the treatment of MSSA infections unless the patients has a significant $\beta$-lactam allergy. Thus the discovery of two cephalosporins ( $\beta$-lactams), ceftaroline and ceftobiprole with in vitro activity against MRSA due to their affinity for the penicillin-binding protein $\mathrm{PBP} 2 \mathrm{a},{ }^{87-90}$ offer great promise in the treatment of MRSA.

\section{Ceftaroline}

Ceftaroline is highly active against MSSA and MRSA, 91,92 hVISA and VISA, ${ }^{93,94}$ and against daptomycin nonsusceptible S. aureus. ${ }^{95}$

Ceftaroline has already been approved for use in the treatment of ABSSSI and community-acquired pneumonia (CAP). It is important to note that the initial licensing studies for pneumonia specifically excluded patients with risk factors for MRSA pneumonia due to the inactivity of the comparator drug ceftriaxone. ${ }^{96}$ There are no randomized controlled trial (RCT) data for more invasive infections, such as bacteremia, endocarditis or osteoarticular infections, however results from case reports and series are encouraging. ${ }^{97-102}$ Likewise, ceftaroline in combination as salvage therapy has been effective in patients with persistent MRSA bacteremia. ${ }^{103}$

Results are yet to be published from a RCT in patients with community-acquired bacterial pneumonia at risk of MRSA infection that was completed in December 2013 (ClinicalTrials.gov NCT01645735), and compared intravenous ceftaroline $600 \mathrm{mg} 8$ hourly versus intravenous ceftriaxone $2 \mathrm{~g}$ once daily plus intravenous vancomycin $15 \mathrm{mg} / \mathrm{kg}$ twice daily (and adjusted based on trough concentrations). A multicenter open-label cohort study evaluating the safety and efficacy of intravenous ceftaroline $600 \mathrm{mg} 8$ hourly in SAB including MRSA bacteremia was recently completed in July 2014 (ClinicalTrials.gov NCT01701219).

Adverse events with ceftaroline are similar to those of other cephalosporins. Headache, rash, and infusion-related adverse events have been reported at rates similar to or less than comparator agents. ${ }^{96,100}$ Transient elevations in liver transaminases and creatinine kinase and the formation of urinary crystals have been reported. The clinical significance of urinary crystals is uncertain but do not represent crystallized drug. Increased rates of hematologic toxicity and rash leading to discontinuation have been reported in off-label use. ${ }^{104}$ In addition, eosinophilic pneumonia has been reported when using ceftaroline for MRSA pneumonia. $^{102,105,106}$

Clinically significant resistance has not yet been reported in clinical settings. An in vitro study of stored MRSA isolates in Australia has demonstrated ceftaroline nonsusceptibility in ST239 MRSA, a multiresistant MRSA strain endemic in hospitals in the Asia-Pacific. ${ }^{107}$ In addition, ceftaroline heteroresistance has been observed in MRSA, hVISA, VISA, daptomycin nonsusceptible, and linezolid nonsusceptible S. aureus laboratory isolates ${ }^{108}$ with mutations seen in PBP2a leading to lower binding affinity, reduced efficacy, and higher ceftaroline MICs. ${ }^{109,110}$

\section{Ceftobiprole}

Ceftobiprole is another antistaphylococcal cephalosporin with greater spectrum of activity than ceftaroline. Similar to ceftaroline, it retains activity against more resistant $S$. aureus strains including those with elevated vancomycin MIC. ${ }^{111}$ Studies in ABSSSI demonstrated noninferiority to vancomycin, ${ }^{112}$ and it was approved for use in Canada, Switzerland, Ukraine, Russia, Azerbaijan, and Hong Kong. ${ }^{113}$ Due to concerns about data integrity, both the United States 
and Europe denied approval for this indication in 2009 to 2010. In a RCT of patients requiring hospitalization for CAP, intravenous ceftobiprole $500 \mathrm{mg}$ twice daily was noninferior to intravenous ceftriaxone $2 \mathrm{~g}$ once daily with or without intravenous linezolid $600 \mathrm{mg}$ twice daily, ${ }^{114}$ however in the microbiologically evaluable population there was only one patient with MRSA pneumonia. Intravenous ceftobiprole $500 \mathrm{mg} 8$ hourly was also noninferior to intravenous ceftazidime 2 g 8 hourly plus intravenous linezolid $600 \mathrm{mg}$ twice daily in the treatment of HAP but not VAP. ${ }^{115}$ Favorable rates of clinical cure and microbiological eradication were observed in those patients with MRSA pneumonia. In a posthoc PK/PD model there was a strong correlation between ceftobiprole exposure and improved clinical cure and microbiological eradication. ${ }^{116}$

Ceftobiprole gained regulatory approval in October 2013 in 12 European states (Austria, Belgium, Denmark, Finland, France, Germany, Norway, Spain, Sweden, and the United Kingdom) for the treatment of CAP and HAP, however it has not been approved for the treatment of VAP. ${ }^{117,118}$ Basilea Pharmaceutica (Basel, Switzerland) does not intend on initiating new phase three trials for ceftobiprole to seek potential regulatory approval in the United States. ${ }^{119}$ It has a comparable adverse effect profile to comparators, similar to other cephalosporins. ${ }^{112,114,115}$

\section{Daptomycin}

Daptomycin belongs to a new cyclic lipopeptide class of antibiotics and was first licensed for human use in 2003. It has a unique mechanism of action, with calcium-dependent binding to the cytoplasmic membrane resulting in rapid membrane depolarization and efflux of potassium. ${ }^{120,121}$ This results in the arrest of DNA, RNA, and protein synthesis and leads to rapid cell death. Importantly, daptomycin is inactivated by pulmonary surfactant and cannot be used in the treatment of pneumonia. It also has poor penetration into cerebrospinal fluid, although this may improve in the setting of inflamed meninges. ${ }^{122}$

Daptomycin is active against methicillin- and vancomycin-resistant staphylococci, and is the only new antibiotic that has a licensing indication for the treatment of SAB and right-sided endocarditis. ${ }^{123}$ Historically, daptomycin has been used as salvage therapy in patients failing vancomycin therapy, particularly with high vancomycin MIC infections, but increasingly it is being used as initial therapy in high inoculum MRSA infections. For example, a recent casecontrol study by Moore et al demonstrated improved survival and lower rates of clinical failure when daptomycin was used in the treatment of high vancomycin MIC MRSA bacteremia, whether as salvage treatment or as early initial treatment. ${ }^{124}$ Although this study suggested better outcomes in elevated vancomycin MIC infections, the results should be interpreted with caution secondary to methodological limitations including a selection bias. A subsequent study attempted to address this issue by selecting patients using a propensity score matching procedure. ${ }^{125}$ Despite showing a mortality benefit with daptomycin compared with vancomycin at 30 days, several limitations preclude generalization of these results; these include the MIC methodology used (automated susceptibility platform) in the study and the small number of patients recruited ( $~ 10 \%$ of all screened patients).

A multicenter open-label RCT is currently recruiting patients to investigate whether intravenous daptomycin 6 to $8 \mathrm{mg} / \mathrm{kg}$ daily is superior to intravenous vancomycin $15 \mathrm{mg} / \mathrm{kg}$ twice daily (and adjusted by trough levels thereafter) in the treatment of MRSA bacteremia with high vancomycin MIC (ClinicalTrials.gov NCT01975662). Hopefully this study will be completed and be able to answer this important question as a similar previous study had to be terminated due to low patient enrollment (ClinicalTrials.gov NCT01287832).

Unfortunately daptomycin has not been the panacea once predicted for treatment of MRSA. Resistance emerged within months of its commercial use, ${ }^{126}$ and in the original licensing study for SAB it was noted that one-third of daptomycin treatment failures were associated with reduced susceptibility to daptomycin. ${ }^{123}$ Prior exposure to vancomycin and retained prosthetic devices have been associated with an increased risk of daptomycin resistance, ${ }^{121,127}$ as well as doses less than $6 \mathrm{mg} / \mathrm{kg}$ (the FDA-licensed dose for SAB and endocarditis) for serious infections such as bacteremia and endocarditis. ${ }^{128}$ This is reflected in the Infectious Diseases Society of America guidelines for treatment of MRSA infections, where daptomycin dosing is recommended at 8 to $10 \mathrm{mg} / \mathrm{kg}$ for complicated bacteremia and in combination with other agents if there has been prior vancomycin treatment failure. ${ }^{16}$ Improved outcomes have been reported if high-dose daptomycin is instituted early in patients with high vancomycin MIC MRSA bacteremia, ${ }^{125,128}$ although resistance has now been reported in high dose therapy. ${ }^{129}$

Daptomycin nonsusceptibility mechanisms are diverse, and are most frequently observed in patients with high bacterial burden infections or ineradicable foci. ${ }^{129,130}$ Various single nucleotide polymorphisms have been observed with mprF mutations generally selected following daptomycin exposure. ${ }^{131}$ Mutations in regulators of cell wall metabolism, such as walKR and cell wall thickening, which are selected for by failing vancomycin therapy, may result in daptomycin cross-resistance. ${ }^{132,133}$ This explains the observed association between daptomycin resistance and reduced vancomycin susceptibility as occurs in hVISA and VISA isolates. ${ }^{131}$ Not surprisingly, this crossresistance has been documented in vitro and in vivo in the absence of prior daptomycin exposure and is largely a clinical problem in the setting of daptomycin salvage therapy. ${ }^{134,135}$

\section{Linezolid}

Linezolid is an oxazolidinone class antibiotic that inhibits bacterial protein synthesis by preventing the formation of the 70S initiation complex with activity against MRSA. Unlike, vancomycin, linezolid achieves high levels in the epithelial lining fluid of the lungs, making it a promising candidate for treatment of patients with HAP, including MRSA. This advantage was subsequently highlighted when a posthoc review of subgroups from two studies showed a survival advantage. ${ }^{136}$ However, the results were received with caution given the study methodology. 
To provide the definitive answer to this question Wunderink et al conducted a multicenter RCT comparing vancomycin to linezolid in the treatment of MRSA pneumonia. ${ }^{137}$ This study included 448 patients with MRSA pneumonia in a modified intention-to-treat population and 348 in a per-protocol population. Both clinical and microbiological cure rates were significantly higher in the linezolid arm compared with vancomycin. The key strength of this study is that it was specifically designed to investigate the comparative efficacy of linezolid to vancomycin for MRSA pneumonia. However, despite stringent randomization, by chance the vancomycin arm had a higher proportion of patients on mechanical ventilation (74\% in vancomycin arm vs. $67 \%$ in linezolid arm) and with MRSA bacteremia ( 11 vs. $5 \%$ ). The study was designed using current vancomycin-dosing regimens, at the time which, based on the recent guidelines, would be considered suboptimal. However, the most discussed finding was the similar 60-day mortality in both treatment arms (vancomycin $17 \%$, linezolid 16\%), despite the greater clinical and microbiological cure rates with linezolid. Possible explanations for this finding include that the study was not powered to detect a mortality difference; and that antibiotics are likely to influence attributable mortality rather than overall mortality especially in critically ill patients. Given this controversy, four subsequent meta-analyses have been conducted and have consistently shown similar efficacies for linezolid and vancomycin for treatment of HAP. ${ }^{138-141}$ The two most recent of these metaanalyses included the data from the above trial $^{138,139}$ and observed similar efficacies for linezolid and vancomycin, including microbiologically proven MRSA pneumonia subgroups.

Linezolid has been compared with vancomycin for SAB in several case series and observational cohorts. ${ }^{142-145}$ Comparable efficacy to vancomycin, in terms of clinical outcomes and mortality, was observed in all studies including metaanalyses for the subgroup of patients with SAB. ${ }^{146,147}$

\section{Tedizolid}

Tedizolid (previously known as torezolid during early studies) is a new oxazolidinone that has been specifically engineered to improve bioavailability and efficacy but reduce toxicity compared with linezolid. It is dosed once daily and its potency is 4 to 16 times greater than linezolid, ${ }^{58,148}$ with activity against linezolid nonsusceptible $S$. aureus isolates. ${ }^{61,148,149}$ Data on its activity against VISA and VRSA are lacking. ${ }^{58,150,151}$ The ESTABLISH-1 trial was a phase three randomized controlled study demonstrating noninferiority of oral tedizolid $200 \mathrm{mg}$ once daily for 6 days compared with oral linezolid $600 \mathrm{mg}$ twice daily for 10 days for treatment of ABSSSI. ${ }^{152}$ Both oral and intravenous formulations were licensed in the United States in June 2014, and it is currently under evaluation in Europe compared with linezolid, tedizolid has less myelotoxicity and gastrointestinal disturbance. ${ }^{149,153}$ In addition, the risk of serotonergic syndrome is negligible due to a lack of monoamine oxidase inhibition at clinically relevant doses. ${ }^{153}$

\section{Quinupristin/Dalfopristin}

Quinupristin/dalfopristin (QD) is a combination of two semisynthetic streptogramin antibiotics (derived from pristina- mycin) in a ratio of 30:70. QD binds to the 50S bacterial ribosome in two sequential steps, and thus inhibits bacterial protein synthesis. Each drug alone is bacteriostatic against susceptible gram-positive organisms including MRSA, but the combination is synergistic and bactericidal. ${ }^{154}$

In vitro data reveal that $\mathrm{QD}$ is broadly active against MRSA isolates, with an $\mathrm{MIC}_{50}$ of $0.5 \mu \mathrm{g} / \mathrm{mL}$ and an $\mathrm{MIC}_{90}$ of $1.0 \mu \mathrm{g} / \mathrm{mL}$ in a study of 10,216 clinical MRSA isolates from the United States and Canada. ${ }^{155}$ Furthermore, the MICs of QD against MRSA were not significantly different from those against MSSA. A subsequent study including isolates from Europe and Asia as well as the Americas had similar findings, with over $99 \%$ of MRSA isolates susceptible. ${ }^{156}$ QD has several notable adverse effects which limit its use, including pain on injection in up to $50 \%$ of patients (necessitating administration through a central venous catheter), myalgias, arthralgias, nausea, and hyperbilirubinemia, each occurring in approximately $10 \%$ of patients in clinical studies. ${ }^{157,158}$

There are no large clinical trials comparing QD with vancomycin or other treatments for severe MRSA infections. Animal models show mixed results, with QD showing rapid bactericidal activity in a $S$. aureus mouse endocarditis model, ${ }^{159}$ but showing inferior results to vancomycin in both a rabbit arthritis model ${ }^{160}$ and an MRSA rabbit endocarditis model. $^{161}$

Most clinical studies of QD have included patients with various gram-positive infections, and the number with MRSA in these studies is quite small. In a multicenter international RCT comparing QD with vancomycin in 298 patients with gram-positive nosocomial pneumonia, QD had similar clinical success $(43.3 \%)$ to vancomycin $(45.3 \%)$ in the all-treated group, but a trend to lower clinical success in the subgroup with proven MRSA infection (19\% in the QD group vs. $40 \%$ in the vancomycin-treated arm). ${ }^{158}$ In phase 2 RCT comparing QD with standard therapy in patients hospitalized with ABSSSIs, seven of nine patients with proven MRSA infections treated with QD had a successful outcome. ${ }^{162}$

The largest published study of the clinical use of QD in severe infections was the report from an open label emergency use program for patients either intolerant of all other options or who had failed previous therapy and had no other available options. ${ }^{157}$ This program enrolled 90 patients from 63 centers in 5 countries. Allergy to or intolerance of other antibiotic options was the reason for enrolment in the majority of patients (70\%). Of the 90 enrolled patients, 70 were for culture-proven MRSA with osteoarticular $(n=40)$, ABSSSI $(n=15)$, and endocarditis $(n=11)$ being the most common foci of infection. Overall 43 patients were bacteremia. The success at days 7 to 14 was $71 \%$, which is not dissimilar to a pooled clinical success rate of $78 \%$ from a metaanalysis of 11 RCTs of vancomycin for MRSA infections. ${ }^{163}$ However, this report contained concerning signals in the subgroup with severe infections, with an overall success rate of only $55 \%$ in endocarditis and $40 \%$ with pneumonia. ${ }^{163}$

\section{Tigecycline}

Tigecycline is a parenteral glycylcycline antibiotic, derived from minocycline. It has in vitro activity against many gram- 
positive bacteria, including MRSA. The main treatment-limiting adverse effect of tigecycline is nausea and vomiting, which occurs in 30 to $40 \%$ of treated patients. ${ }^{164,165}$

There are substantial clinical trial data available on the use of tigecycline for intra-abdominal infections, complicated ABSSSIs, and nosocomial pneumonia, but there are insufficient data available specifically assessing the role of tigecycline in invasive MRSA infections. Multiple studies have assessed the in vitro tigecycline susceptibility of various MRSA strains and they have consistently found that tigecycline is highly active against MRSA in vitro. For example, two studies from the United States found $98.2 \%$ of 1,989 community-acquired MRSA isolates ${ }^{166}$ and $100 \%$ of 1,692 unselected MRSA isolates ${ }^{167}$ were susceptible. European studies have had similar findings. ${ }^{168,169}$

In animal models, tigecycline has comparable activity to vancomycin against MRSA, in a MRSA rat thigh infection model $^{170}$ and to teicoplanin in a rabbit osteomyelitis model. ${ }^{171}$ In most randomized trials, there are too few MRSA patients to draw conclusions from. For example, in a phase $3 \mathrm{~b}$ RCT of 571 patients with complicated ABSSSIs, the overall cure rate was $77.5 \%$ in the tigecycline group overall, and $69 \%$ in the 36 patients with MRSA infection. ${ }^{172}$ In a RCT of high-dose tigecycline in 108 patients with HAP, there were only 6 patients with proven MRSA infections. ${ }^{173}$ The only RCT to focus on MRSA patients was a phase 3 RCT enrolling patients with MRSA or vancomycin-resistant enterococcal infections. ${ }^{165}$ Of the 117 microbiologically evaluable MRSA patients, the clinical cure rate was comparable in the tigecycline group (81.4\%) to vancomycin or linezolid (83.9\%).

The FDA issued a safety warning in 2010 and a black box warning in 2013 regarding increased risk of mortality in patients treated with tigecycline compared with other antibiotics. These warnings prompted several meta-analyses to be published, most of which had similar findings: a small but significant excess mortality risk in the tigecycline arm over the comparator arm in RCTs of serious infections, ${ }^{164,174-176}$ particularly patients with bacteremia and VAP. ${ }^{177}$ The number of patients with proven MRSA infections in these metaanalyses was either small or not specified, but subgroup analysis by organism type (gram-positive vs. gram-negative) found no difference in the mortality excess by organism type. $^{164,175}$ The paradox of higher mortality and lower cure despite excellent in vitro activity is thought to be due to PK/PD considerations including high protein biding, an inadequate AUC/MIC with standard dosing, poor serum concentrations, and penetration into some tissues. ${ }^{173,178-180}$

\section{Conclusions}

In the treatment of MRSA, vancomycin remains a viable option. Despite this antibiotic being in clinical use for over 50 years there still remains uncertainty about the best dosing strategy. However, new insights suggest improved outcomes when dosing to a PK/PD target. The implications of these observations are a move toward individualized dosing. However, before implementation, numerous practicalities need to be resolved including real-time AUC measurements or calcu- lation and appropriate expertise to interpret the results and make appropriate modifications. Until these hurdles are addressed it is likely that we will continue to dose using an AUC surrogate such as vancomycin trough concentrations. It should be noted that aggressive dosing and appropriate sampling (i.e., trough levels) are required to make suitable dose modifications. Nevertheless, individualized dosing should be explored in selected patient populations like the critically ill or in intensive care.

Lipoglycopeptides as a class, representing three agents, all show in vitro potency greater than vancomycin. However, their long half-lives and complex PKs (especially oritavancin) may preclude these agents being used in critically ill patients. In addition, the black box warning associated with telavancin would further reduce its current role. Nevertheless, these agents provide some alternatives when no other options are available.

Anti-MRSA cephalosporins (ceftobiprole and ceftaroline) provide great promise in the treatment of MRSA. Their clinical utility remains to be seen, however, as resistance has already been observed in vitro with likely identified mutations; consequently, monitoring for broader emergence of resistance will be required. Ceftobiprole is a viable option in the treatment of CAP and HAP with results yet to be published for ceftaroline. Similarly, a bacteremia study comparing ceftaroline to vancomycin has only just been completed. Nevertheless, these agents should be reserved for patients with MRSA infections as it is likely that usage will be associated with increased rates resistance.

Daptomycin is currently the only antibiotic to have shown noninferiority to vancomycin in the treatment of MRSA bacteremia. Daptomycin resistance and cross-resistance in the setting of reduced vancomycin susceptibility raises concerns about widespread use of this agent. This may in part be explained by initial inadequate dosing. Two retrospective cohort studies indicate a possible advantage of daptomycin over vancomycin in infections caused by elevated vancomycin MIC. The results of an open-labeled trial to address this question are thus eagerly anticipated.

No drug till date has shown superiority to vancomycin in the treatment of MRSA infections with the possible exception of linezolid in HAP. As discussed, the absence of a mortality benefit despite increased clinical cure has led to much debate. Nevertheless, on balance linezolid should always be considered an option in the treatment MRSA-proven HAP. Whether these strengths and features are agent or class specific are unclear but will likely be answered with the marketing of tedizolid.

Although QD has good in vitro activity against MRSA, there are insufficient data to recommend its use as a first-line agent. In addition, administration issues (the requirement of a central line) and the significant adverse effects further impacts its possible role, as either salvage therapy or as an alternative in patients with multiple drug allergies. Similarly, tigecycline cannot be recommended as first-line therapy in serious MRSA infections.

In conclusion, there has been a welcome increase in the number of agents available for the treatment of MRSA. The 
exact role and choice of agent needs to be defined. Hopefully, this will not take as long as it has taken us to determine the optimal vancomycin dosing strategy.

\section{References}

1 Boucher HW, Talbot GH, Bradley JS, et al. Bad bugs, no drugs: no ESKAPE! An update from the Infectious Diseases Society of America. Clin Infect Dis 2009;48(1):1-12

2 Sievert DM, Ricks P, Edwards JR, et al; National Healthcare Safety Network (NHSN) Team and Participating NHSN Facilities. Antimicrobial-resistant pathogens associated with healthcare-associated infections: summary of data reported to the National Healthcare Safety Network at the Centers for Disease Control and Prevention, 2009-2010. Infect Control Hosp Epidemiol 2013; $34(1): 1-14$

3 Lodise TP, McKinnon PS. Clinical and economic impact of methicillin resistance in patients with Staphylococcus aureus bacteremia. Diagn Microbiol Infect Dis 2005;52(2):113-122

4 Dantes R, Mu Y, Belflower R, et al; Emerging Infections ProgramActive Bacterial Core Surveillance MRSA Surveillance Investigators. National burden of invasive methicillin-resistant Staphylococcus aureus infections, United States, 2011. JAMA Intern Med 2013;173(21):1970-1978

5 Barna JC, Williams DH. The structure and mode of action of glycopeptide antibiotics of the vancomycin group. Annu Rev Microbiol 1984;38:339-357

6 Howden BP, Davies JK, Johnson PD, Stinear TP, Grayson ML. Reduced vancomycin susceptibility in Staphylococcus aureus, including vancomycin-intermediate and heterogeneous vancomycin-intermediate strains: resistance mechanisms, laboratory detection, and clinical implications. Clin Microbiol Rev 2010; 23(1):99-139

7 Craig WA. Basic pharmacodynamics of antibacterials with clinical applications to the use of beta-lactams, glycopeptides, and linezolid. Infect Dis Clin North Am 2003;17(3):479-501

8 Rybak MJ. The pharmacokinetic and pharmacodynamic properties of vancomycin. Clin Infect Dis 2006;42(Suppl 1): S35-S39

9 Rybak M, Lomaestro B, Rotschafer JC, et al. Therapeutic monitoring of vancomycin in adult patients: a consensus review of the American Society of Health-System Pharmacists, the Infectious Diseases Society of America, and the Society of Infectious Diseases Pharmacists. Am J Health Syst Pharm 2009;66(1): 82-98

10 Moise PA, Forrest A, Bhavnani SM, Birmingham MC, Schentag JJ. Area under the inhibitory curve and a pneumonia scoring system for predicting outcomes of vancomycin therapy for respiratory infections by Staphylococcus aureus. Am J Health Syst Pharm 2000;57(Suppl 2):S4-S9

11 Moise-Broder PA, Forrest A, Birmingham MC, Schentag JJ. Pharmacodynamics of vancomycin and other antimicrobials in patients with Staphylococcus aureus lower respiratory tract infections. Clin Pharmacokinet 2004;43(13):925-942

12 Avent ML, Vaska VL, Rogers BA, et al. Vancomycin therapeutics and monitoring: a contemporary approach. Intern Med J 2013; 43(2):110-119

13 Neely MN, Youn G, Jones B, et al. Are vancomycin trough concentrations adequate for optimal dosing? Antimicrob Agents Chemother 2014;58(1):309-316

14 Leu WJ, Liu YC, Wang HW, Chien HY, Liu HP, Lin YM. Evaluation of a vancomycin dosing nomogram in achieving high target trough concentrations in Taiwanese patients. Int J Infect Dis 2012; 16(11):e804-e810

15 Kullar R, Davis SL, Taylor TN, Kaye KS, Rybak MJ. Effects of targeting higher vancomycin trough levels on clinical outcomes and costs in a matched patient cohort. Pharmacotherapy 2012; 32(3):195-201

16 Liu C, Bayer A, Cosgrove SE, et al; Infectious Diseases Society of America. Clinical practice guidelines by the infectious diseases society of america for the treatment of methicillin-resistant Staphylococcus aureus infections in adults and children. Clin Infect Dis 2011;52(3):e18-e55

17 Patel N, Pai MP, Rodvold KA, Lomaestro B, Drusano GL, Lodise TP. Vancomycin: we can't get there from here. Clin Infect Dis 2011; 52(8):969-974

18 Nunn MO, Corallo CE, Aubron C, Poole S, Dooley MJ, Cheng AC. Vancomycin dosing: assessment of time to therapeutic concentration and predictive accuracy of pharmacokinetic modeling software. Ann Pharmacother 2011;45(6):757-763

19 Wang JT, Fang CT, Chen YC, Chang SC. Necessity of a loading dose when using vancomycin in critically ill patients. J Antimicrob Chemother 2001;47(2):246

20 Mohammedi I, Descloux E, Argaud L, Le Scanff J, Robert D. Loading dose of vancomycin in critically ill patients: $15 \mathrm{mg} / \mathrm{kg}$ is a better choice than $500 \mathrm{mg}$. Int J Antimicrob Agents 2006;27(3):259-262

21 Thomson AH, Staatz CE, Tobin CM, Gall M, Lovering AM. Development and evaluation of vancomycin dosage guidelines designed to achieve new target concentrations. J Antimicrob Chemother 2009;63(5):1050-1057

22 James JK, Palmer SM, Levine DP, Rybak MJ. Comparison of conventional dosing versus continuous-infusion vancomycin therapy for patients with suspected or documented gram-positive infections. Antimicrob Agents Chemother 1996;40(3): 696-700

23 Wysocki M, Delatour F, Faurisson F, et al. Continuous versus intermittent infusion of vancomycin in severe Staphylococcal infections: prospective multicenter randomized study. Antimicrob Agents Chemother 2001;45(9):2460-2467

24 Cataldo MA, Tacconelli E, Grilli E, Pea F, Petrosillo N. Continuous versus intermittent infusion of vancomycin for the treatment of Gram-positive infections: systematic review and meta-analysis. J Antimicrob Chemother 2012;67(1):17-24

25 Ingram PR, Lye DC, Tambyah PA, Goh WP, Tam VH, Fisher DA. Risk factors for nephrotoxicity associated with continuous vancomycin infusion in outpatient parenteral antibiotic therapy. J Antimicrob Chemother 2008;62(1):168-171

26 Prakash V, Lewis JS II, Jorgensen JH. Vancomycin MICs for methicillin-resistant Staphylococcus aureus isolates differ based upon the susceptibility test method used. Antimicrob Agents Chemother 2008;52(12):4528

27 van Hal SJ, Barbagiannakos T, Jones M, et al. Methicillin-resistant Staphylococcus aureus vancomycin susceptibility testing: methodology correlations, temporal trends and clonal patterns. J Antimicrob Chemother 2011;66(10):2284-2287

28 Holmes NE, Turnidge JD, Munckhof WJ, et al. Vancomycin AUC/ MIC ratio and 30-day mortality in patients with Staphylococcus aureus bacteremia. Antimicrob Agents Chemother 2013;57(4): 1654-1663

29 Rybak MJ, Vidaillac C, Sader HS, et al. Evaluation of vancomycin susceptibility testing for methicillin-resistant Staphylococcus aureus: comparison of Etest and three automated testing methods. J Clin Microbiol 2013;51(7):2077-2081

30 Neuner EA, Casabar E, Reichley R, McKinnon PS. Clinical, microbiologic, and genetic determinants of persistent methicillinresistant Staphylococcus aureus bacteremia. Diagn Microbiol Infect Dis 2010;67(3):228-233

31 Ghosh N, Chavada R, Maley M, van Hal SJ. Impact of source of infection and vancomycin AUC0-24 /MICBMD targets on treatment failure in patients with methicillin-resistant Staphylococcus aureus bacteraemia. Clin Microbiol Infect 2014

32 Kullar R, Davis SL, Levine DP, Rybak MJ. Impact of vancomycin exposure on outcomes in patients with methicillin-resistant 
Staphylococcus aureus bacteremia: support for consensus guidelines suggested targets. Clin Infect Dis 2011;52(8):975-981

33 Zelenitsky S, Rubinstein E, Ariano R, et al; Cooperative Antimicrobial Therapy of Septic Shock-CATSS Database Research Group. Vancomycin pharmacodynamics and survival in patients with methicillin-resistant Staphylococcus aureus-associated septic shock. Int J Antimicrob Agents 2013;41(3):255-260

34 Brown J, Brown K, Forrest A. Vancomycin AUC24/MIC ratio in patients with complicated bacteremia and infective endocarditis due to methicillin-resistant Staphylococcus aureus and its association with attributable mortality during hospitalization. Antimicrob Agents Chemother 2012;56(2):634-638

35 Gawronski KM, Goff DA, Brown J, Khadem TM, Bauer KA. A stewardship program's retrospective evaluation of vancomycin AUC24/MIC and time to microbiological clearance in patients with methicillin-resistant Staphylococcus aureus bacteremia and osteomyelitis. Clin Ther 2013;35(6):772-779

36 Jung Y, Song KH, Cho Je, et al. Area under the concentration-time curve to minimum inhibitory concentration ratio as a predictor of vancomycin treatment outcome in methicillin-resistant Staphylococcus aureus bacteraemia. Int J Antimicrob Agents 2014; 43(2):179-183

37 Clinical and Laboratory Standards Institute. Methods for Dilution Antimicrobial Susceptibility Tests for Bacteria That Grow Aerobically: Approved Standard. CLSI document M07-A7. 7th ed. Wayne, PA: CLSI; 2006

38 van Hal SJ, Lodise TP, Paterson DL. The clinical significance of vancomycin minimum inhibitory concentration in Staphylococcus aureus infections: a systematic review and meta-analysis. Clin Infect Dis 2012;54(6):755-771

39 Holmes NE, Turnidge JD, Munckhof WJ, et al. Antibiotic choice may not explain poorer outcomes in patients with Staphylococcus aureus bacteremia and high vancomycin minimum inhibitory concentrations. J Infect Dis 2011;204(3):340-347

40 Aguado JM, San-Juan R, Lalueza A, et al. High vancomycin MIC and complicated methicillin-susceptible Staphylococcus aureus bacteremia. Emerg Infect Dis 2011;17(6):1099-1102

41 van Hal SJ, Jones M, Gosbell IB, Paterson DL. Vancomycin heteroresistance is associated with reduced mortality in ST239 methicillin-resistant Staphylococcus aureus blood stream infections. PLoS ONE 2011;6(6):e21217

42 van Hal SJ, Paterson DL. Systematic review and meta-analysis of the significance of heterogeneous vancomycin-intermediate Staphylococcus aureus isolates. Antimicrob Agents Chemother 2011;55(1):405-410

43 Horne KC, Howden BP, Grabsch EA, et al. Prospective comparison of the clinical impacts of heterogeneous vancomycin-intermediate methicillin-resistant Staphylococcus aureus (MRSA) and vancomycin-susceptible MRSA. Antimicrob Agents Chemother 2009; 53(8):3447-3452

44 Peleg AY, Monga D, Pillai S, Mylonakis E, Moellering RC Jr, Eliopoulos GM. Reduced susceptibility to vancomycin influences pathogenicity in Staphylococcus aureus infection. J Infect Dis 2009;199(4):532-536

45 Soriano A, Marco F, Martínez JA, et al. Influence of vancomycin minimum inhibitory concentration on the treatment of methicillin-resistant Staphylococcus aureus bacteremia. Clin Infect Dis 2008;46(2):193-200

46 Thwaites GE, Edgeworth JD, Gkrania-Klotsas E, et al; UK Clinical Infection Research Group. Clinical management of Staphylococcus aureus bacteraemia. Lancet Infect Dis 2011;11(3):208-222

47 Bailey EM, Rybak MJ, Kaatz GW. Comparative effect of protein binding on the killing activities of teicoplanin and vancomycin. Antimicrob Agents Chemother 1991;35(6):1089-1092

48 Svetitsky S, Leibovici L, Paul M. Comparative efficacy and safety of vancomycin versus teicoplanin: systematic review and meta-analysis. Antimicrob Agents Chemother 2009;53(10): 4069-4079
49 Yoon YK, Park DW, Sohn JW, et al. Multicenter prospective observational study of the comparative efficacy and safety of vancomycin versus teicoplanin in patients with health careassociated methicillin-resistant Staphylococcus aureus bacteremia.. Antimicrob Agents Chemother 2014;58:317-324

50 Chang HJ, Hsu PC, Yang CC, et al. Influence of teicoplanin MICs on treatment outcomes among patients with teicoplanin-treated methicillin-resistant Staphylococcus aureus bacteraemia: a hospital-based retrospective study. J Antimicrob Chemother 2012; 67(3):736-741

51 Chen KY, Chang HJ, Hsu PC, et al. Relationship of teicoplanin MICs to treatment failure in teicoplanin-treated patients with methicillin-resistant Staphylococcus aureus pneumonia. J Microbiol Immunol Infect 2013;46(3):210-216

52 Higgins DL, Chang R, Debabov DV, et al. Telavancin, a multifunctional lipoglycopeptide, disrupts both cell wall synthesis and cell membrane integrity in methicillin-resistant Staphylococcus aureus. Antimicrob Agents Chemother 2005;49(3):1127-1134

53 Saravolatz LD, Stein GE, Johnson LB. Telavancin: a novel lipoglycopeptide. Clin Infect Dis 2009;49(12):1908-1914

54 Belley A, McKay GA, Arhin FF, et al. Oritavancin disrupts membrane integrity of Staphylococcus aureus and vancomycin-resistant enterococci to effect rapid bacterial killing. Antimicrob Agents Chemother 2010;54(12):5369-5371

55 McKay GA, Beaulieu S, Arhin FF, et al. Time-kill kinetics of oritavancin and comparator agents against Staphylococcus aureus, Enterococcus faecalis and Enterococcus faecium. J Antimicrob Chemother 2009;63(6):1191-1199

56 Bozdogan B, Esel D, Whitener C, Browne FA, Appelbaum PC. Antibacterial susceptibility of a vancomycin-resistant Staphylococcus aureus strain isolated at the Hershey Medical Center. J Antimicrob Chemother 2003;52(5):864-868

57 Leuthner KD, Cheung CM, Rybak MJ. Comparative activity of the new lipoglycopeptide telavancin in the presence and absence of serum against 50 glycopeptide non-susceptible staphylococci and three vancomycin-resistant Staphylococcus aureus. J Antimicrob Chemother 2006;58(2):338-343

58 Rybak JM, Barber KE, Rybak MJ. Current and prospective treatments for multidrug-resistant gram-positive infections. Expert Opin Pharmacother 2013;14(14):1919-1932

59 Rodvold KA, McConeghy KW. Methicillin-resistant Staphylococcus aureus therapy: past, present, and future. Clin Infect Dis 2014; 58(Suppl 1):S20-S27

60 Leonard SN, Szeto YG, Zolotarev M, Grigoryan IV. Comparative in vitro activity of telavancin, vancomycin and linezolid against heterogeneously vancomycin-intermediate Staphylococcus aureus (hVISA). Int J Antimicrob Agents 2011;37(6):558-561

61 Moellering RC Jr. Tedizolid: a novel oxazolidinone for Grampositive infections. Clin Infect Dis 2014;58(Suppl 1):S1-S3

62 Rubinstein E, Lalani T, Corey GR, et al; ATTAIN Study Group. Telavancin versus vancomycin for hospital-acquired pneumonia due to gram-positive pathogens. Clin Infect Dis 2011;52(1):31-40

63 Corey GR, Kollef MH, Shorr AF, et al. Telavancin for hospitalacquired pneumonia: clinical response and 28-day survival. Antimicrob Agents Chemother 2014;58(4):2030-2037

64 Stryjewski ME, Lentnek A, O'Riordan W, et al. A randomized Phase 2 trial of telavancin versus standard therapy in patients with uncomplicated Staphylococcus aureus bacteremia: the ASSURE study. BMC Infect Dis 2014;14:289

65 Stryjewski ME, O'Riordan WD, Lau WK, et al; FAST Investigator Group. Telavancin versus standard therapy for treatment of complicated skin and soft-tissue infections due to gram-positive bacteria. Clin Infect Dis 2005;40(11):1601-1607

66 Stryjewski ME, Graham DR, Wilson SE, et al; Assessment of Telavancin in Complicated Skin and Skin-Structure Infections Study. Telavancin versus vancomycin for the treatment of complicated skin and skin-structure infections caused by grampositive organisms. Clin Infect Dis 2008;46(11):1683-1693 
67 Zhanel GG, Calic D, Schweizer F, et al. New lipoglycopeptides: a comparative review of dalbavancin, oritavancin and telavancin. Drugs 2010;70(7):859-886

68 Burke SL, Rose WE. New pharmacological treatments for methicillin-resistant Staphylococcus aureus infections. Expert Opin Pharmacother 2014;15(4):483-491

69 Jones RN, Sader HS, Flamm RK. Update of dalbavancin spectrum and potency in the USA: report from the SENTRY Antimicrobial Surveillance Program (2011). Diagn Microbiol Infect Dis 2013; 75(3):304-307

70 Citron DM, Tyrrell KL, Goldstein EJ. Comparative in vitro activities of dalbavancin and seven comparator agents against 41 Staphylococcus species cultured from osteomyelitis infections and 18 VISA and hVISA strains. Diagn Microbiol Infect Dis 2014;79(4): 438-440

71 Boucher HW, Wilcox M, Talbot GH, Puttagunta S, Das AF, Dunne MW. Once-weekly dalbavancin versus daily conventional therapy for skin infection. N Engl J Med 2014;370(23):2169-2179

72 Food and Drug Administration. Center for Drug Evaluation and Research. Guidance for industry acute bacterial skin and skin structure infections: developing drugs for treatment, 2013. Available at: http://www.fda.gov/downloads/Drugs/.../Guidances/ucm071185.pdf. Accessed August 15, 2014

73 Ambrose PG, Drusano GL, Craig WA. In vivo activity of oritavancin in animal infection models and rationale for a new dosing regimen in humans. Clin Infect Dis 2012;54(Suppl 3): S220-S228

74 Tice A. Oritavancin: a new opportunity for outpatient therapy of serious infections. Clin Infect Dis 2012;54(Suppl 3):S239-S243

75 Arhin FF, Sarmiento I, Belley A, et al. Effect of polysorbate 80 on oritavancin binding to plastic surfaces: implications for susceptibility testing. Antimicrob Agents Chemother 2008;52(5): 1597-1603

76 Karaoui LR, El-Lababidi R, Chahine EB. Oritavancin: an investigational lipoglycopeptide antibiotic. Am J Health Syst Pharm 2013; 70(1):23-33

77 Lin G, Pankuch G, Appelbaum PC, Kosowska-Shick K. Antistaphylococcal activity of oritavancin and its synergistic effect in combination with other antimicrobial agents. Antimicrob Agents Chemother 2014;58(10):6251-6254

78 Arhin FF, Sarmiento I, Moeck G. In vitro activities of oritavancin and comparators against meticillin-resistant Staphylococcus aureus (MRSA) isolates harbouring the novel mecC gene. Int J Antimicrob Agents 2014;44(1):65-68

79 Mendes RE, Sader HS, Flamm RK, Farrell DJ, Jones RN. Oritavancin activity against Staphylococcus aureus causing invasive infections in U.S. and European hospitals: a 5-year international surveillance program. Antimicrob Agents Chemother 2014; 58(5):2921-2924

80 Corey GR, Kabler H, Mehra P, et al; SOLO I Investigators. Singledose oritavancin in the treatment of acute bacterial skin infections. N Engl J Med 2014;370(23):2180-2190

81 Chambers HF. Pharmacology and the treatment of complicated skin and skin-structure infections. N Engl J Med 2014;370(23): 2238-2239

82 Chang FY, Peacock JE Jr, Musher DM, et al. Staphylococcus aureus bacteremia: recurrence and the impact of antibiotic treatment in a prospective multicenter study. Medicine (Baltimore) 2003; 82(5):333-339

83 Stryjewski ME, Szczech LA, Benjamin DK Jr, et al. Use of vancomycin or first-generation cephalosporins for the treatment of hemodialysis-dependent patients with methicillin-susceptible Staphylococcus aureus bacteremia. Clin Infect Dis 2007;44(2): 190-196

$84 \mathrm{Kim} \mathrm{SH}$, Kim KH, Kim HB, et al. Outcome of vancomycin treatment in patients with methicillin-susceptible Staphylococcus aureus bacteremia. Antimicrob Agents Chemother 2008;52(1):192-197
85 Schweizer ML, Furuno JP, Harris AD, et al. Comparative effectiveness of nafcillin or cefazolin versus vancomycin in methicillinsusceptible Staphylococcus aureus bacteremia. BMC Infect Dis 2011;11:279

86 Chan KE, Warren HS, Thadhani RI, et al. Prevalence and outcomes of antimicrobial treatment for Staphylococcus aureus bacteremia in outpatients with ESRD. J Am Soc Nephrol 2012;23(9): 1551-1559

87 Chambers HF. Ceftobiprole: in-vivo profile of a bactericidal cephalosporin. Clin Microbiol Infect 2006;12(Suppl 2):17-22

88 Kosowska-Shick K, McGhee PL, Appelbaum PC. Affinity of ceftaroline and other beta-lactams for penicillin-binding proteins from Staphylococcus aureus and Streptococcus pneumoniae. Antimicrob Agents Chemother 2010;54(5):1670-1677

89 Steed ME, Rybak MJ. Ceftaroline: a new cephalosporin with activity against resistant gram-positive pathogens. Pharmacotherapy 2010;30(4):375-389

90 Richter SS, Heilmann KP, Dohrn CL, et al. Activity of ceftaroline and epidemiologic trends in Staphylococcus aureus isolates collected from 43 medical centers in the United States in 2009. Antimicrob Agents Chemother 2011;55(9):4154-4160

91 Pfaller MA, Flamm RK, Sader HS, Jones RN. Ceftaroline activity against bacterial organisms isolated from acute bacterial skin and skin structure infections in United States medical centers (20092011). Diagn Microbiol Infect Dis 2014;78(4):422-428

92 Flamm RK, Sader HS, Jones RN. Ceftaroline activity against organisms isolated from respiratory tract infections in USA hospitals: results from the AWARE Program, 2009-2011. Diagn Microbiol Infect Dis 2014;78(4):437-442

93 Werth BJ, Steed ME, Kaatz GW, Rybak MJ. Evaluation of ceftaroline activity against heteroresistant vancomycin-intermediate Staphylococcus aureus and vancomycin-intermediate methicillin-resistant S. aureus strains in an in vitro pharmacokinetic/ pharmacodynamic model: exploring the "seesaw effect". Antimicrob Agents Chemother 2013;57(6):2664-2668

94 Werth BJ, Barber KE, Ireland CE, Rybak MJ. Evaluation of ceftaroline, vancomycin, daptomycin, or ceftaroline plus daptomycin against daptomycin-nonsusceptible methicillin-resistant Staphylococcus aureus in an in vitro pharmacokinetic/pharmacodynamic model of simulated endocardial vegetations. Antimicrob Agents Chemother 2014;58(6):3177-3181

95 Werth BJ, Sakoulas G, Rose WE, Pogliano J, Tewhey R, Rybak MJ. Ceftaroline increases membrane binding and enhances the activity of daptomycin against daptomycin-nonsusceptible vancomycin-intermediate Staphylococcus aureus in a pharmacokinetic/ pharmacodynamic model. Antimicrob Agents Chemother 2013; 57(1):66-73

96 File TM Jr, Wilcox MH, Stein GE. Summary of ceftaroline fosamil clinical trial studies and clinical safety. Clin Infect Dis 2012;55 (Suppl 3):S173-S180

97 Arshad S, Hartman P, Zervos MJ. A novel treatment option for MRSA pneumonia: ceftaroline fosamil-yielding new hope in the fight against a persistent infection. Expert Rev Anti Infect Ther 2014;12(7):727-729

98 Pasquale TR, Tan MJ, Trienski TL, File TM Jr. Methicillin-resistant Staphylococcus aureus nosocomial pneumonia patients treated with ceftaroline: retrospective case series of 10 patients. J Chemother 2013:Y0000000156

99 Lin JC, Aung G, Thomas A, Jahng M, Johns S, Fierer J. The use of ceftaroline fosamil in methicillin-resistant Staphylococcus aureus endocarditis and deep-seated MRSA infections: a retrospective case series of 10 patients. J Infect Chemother 2013;19(1):42-49

100 Casapao AM, Davis SL, Barr VO, et al. Large retrospective evaluation of the effectiveness and safety of ceftaroline fosamil therapy. Antimicrob Agents Chemother 2014;58(5):2541-2546

101 Tattevin P, Boutoille D, Vitrat V, et al. Salvage treatment of methicillin-resistant staphylococcal endocarditis with 
ceftaroline: a multicenter observational study. J Antimicrob Chemother 2014;69(7):2010-2013

102 Polenakovik HM, Pleiman CM. Ceftaroline for meticillin-resistant Staphylococcus aureus bacteraemia: case series and review of the literature. Int J Antimicrob Agents 2013;42(5):450-455

103 Sakoulas G, Moise PA, Casapao AM, et al. Antimicrobial Salvage Therapy for Persistent Staphylococcal Bacteremia Using Daptomycin Plus Ceftaroline. Clin Ther 2014

104 Jain R, Chan JD, Rogers L, Dellit TH, Lynch JB, Pottinger PS. High incidence of discontinuations due to adverse events in patients treated with ceftaroline. Pharmacotherapy 2014;34(7):758-763

105 Griffiths CL, Gutierrez KC, Pitt RD, Lovell RD. Eosinophilic pneumonia induced by ceftaroline. Am J Health Syst Pharm 2014; 71(5):403-406

106 Desai KR, Burdette SD, Polenakovik HM, Hagaman J, Pleiman CM. Ceftaroline-induced eosinophilic pneumonia. Pharmacotherapy 2013;33(7):e166-e169

107 Espedido BA, Jensen SO, van Hal SJ. Ceftaroline fosamil salvage therapy: an option for reduced-vancomycin-susceptible MRSA bacteraemia. J Antimicrob Chemother 2014; November 17 epub ahead of print

108 Saravolatz SN, Martin H, Pawlak J, Johnson LB, Saravolatz LD. Ceftaroline-heteroresistant Staphylococcus aureus. Antimicrob Agents Chemother 2014;58(6):3133-3136

109 Mendes RE, Tsakris A, Sader HS, et al. Characterization of methicillin-resistant Staphylococcus aureus displaying increased MICs of ceftaroline. J Antimicrob Chemother 2012; 67(6):1321-1324

110 Alm RA, McLaughlin RE, Kos VN, Sader HS, Iaconis JP, Lahiri SD. Analysis of Staphylococcus aureus clinical isolates with reduced susceptibility to ceftaroline: an epidemiological and structural perspective. J Antimicrob Chemother 2014;69(8): 2065-2075

111 Chong YP, Park SJ, Kim HS, et al. In vitro activities of ceftobiprole, dalbavancin, daptomycin, linezolid, and tigecycline against methicillin-resistant Staphylococcus aureus blood isolates: stratified analysis by vancomycin MIC. Diagn Microbiol Infect Dis 2012; 73(3):264-266

112 Noel GJ, Bush K, Bagchi P, Ianus J, Strauss RS. A randomized, double-blind trial comparing ceftobiprole medocaril with vancomycin plus ceftazidime for the treatment of patients with complicated skin and skin-structure infections. Clin Infect Dis 2008; 46(5):647-655

113 Johnson and Johnson Pharmaceutical Research and Development. FDA Issues Complete Response Letter for Ceftobiprole. 2009. Available at: http://www.investor.jnj.com/releasedetail. cfm?ReleaseID $=433517$.Accessed 17 November, 2013

114 Nicholson SC, Welte T, File TM Jr, et al. A randomised, doubleblind trial comparing ceftobiprole medocaril with ceftriaxone with or without linezolid for the treatment of patients with community-acquired pneumonia requiring hospitalisation. Int J Antimicrob Agents 2012;39(3):240-246

115 Awad SS, Rodriguez AH, Chuang YC, et al. A phase 3 randomized double-blind comparison of ceftobiprole medocaril versus ceftazidime plus linezolid for the treatment of hospital-acquired pneumonia. Clin Infect Dis 2014

116 Muller AE, Punt N, Mouton JW. Exposure to ceftobiprole is associated with microbiological eradication and clinical cure in patients with nosocomial pneumonia. Antimicrob Agents Chemother 2014;58(5):2512-2519

117 Pharmaceutica B. Basilea's antibiotic ceftobiprole obtains regulatory approval in Europe for pneumonia 2013. Available at: http://www.basilea.com/chameleon/public/584f9d1e-4298e47c-0475-a5e5e5288ded/582542. Accessed December 17, 2014

118 Pharmaceutica B. Basilea to launch Zevtera/Mabelio (ceftobiprole medocaril) in Europe through a commercial services provider 2014. Available at: http://www.basilea.com/chameleon/public/ 87dd1a16-2523-e4d7-1ee6-1d7fe10b7b29/635582. Accessed December 17, 2014

119 Pharmaceutica B. Basilea provides update on ceftobiprole's U.S regulatory status 2014. Available at: http://www.basilea.com/ chameleon/public/de7cde4b-8150-0816-4ebb-77bfe8cb1ef5/ 620981 A. Accessed December 17, 2014

120 Steenbergen JN, Alder J, Thorne GM, Tally FP. Daptomycin: a lipopeptide antibiotic for the treatment of serious Gram-positive infections. J Antimicrob Chemother 2005;55(3):283-288

121 Boucher HW, Sakoulas G. Perspectives on Daptomycin resistance, with emphasis on resistance in Staphylococcus aureus. Clin Infect Dis 2007;45(5):601-608

122 Gerber P, Stucki A, Acosta F, Cottagnoud M, Cottagnoud P. Daptomycin is more efficacious than vancomycin against a methicillin-susceptible Staphylococcus aureus in experimental meningitis. J Antimicrob Chemother 2006;57(4):720-723

123 Fowler VG Jr, Boucher HW, Corey GR, et al; S. aureus Endocarditis and Bacteremia Study Group. Daptomycin versus standard therapy for bacteremia and endocarditis caused by Staphylococcus aureus. N Engl J Med 2006;355(7):653-665

124 Moore CL, Osaki-Kiyan P, Haque NZ, Perri MB, Donabedian S, Zervos MJ. Daptomycin versus vancomycin for bloodstream infections due to methicillin-resistant Staphylococcus aureus with a high vancomycin minimum inhibitory concentration: a casecontrol study. Clin Infect Dis 2012;54(1):51-58

125 Murray KP, Zhao JJ, Davis SL, et al. Early use of daptomycin versus vancomycin for methicillin-resistant Staphylococcus aureus bacteremia with vancomycin . minimum inhibitory concentration $>1$ mg/L: a matched cohort study. Clin Infect Dis 2013;56:1562-1569

126 Mangili A, Bica I, Snydman DR, Hamer DH. Daptomycin-resistant, methicillin-resistant Staphylococcus aureus bacteremia. Clin Infect Dis 2005;40(7):1058-1060

127 Moise PA, Smyth DS, El-Fawal N, et al. Microbiological effects of prior vancomycin use in patients with methicillin-resistant Staphylococcus aureus bacteraemia. J Antimicrob Chemother 2008;61(1):85-90

128 Gould IM, Miró JM, Rybak MJ. Daptomycin: the role of high-dose and combination therapy for Gram-positive infections. Int J Antimicrob Agents 2013;42(3):202-210

129 Gasch O, Camoez M, Domínguez MA, et al; REIPI/GEIH study groups. Emergence of resistance to daptomycin in a cohort of patients with methicillin-resistant Staphylococcus aureus persistent bacteraemia treated with daptomycin. J Antimicrob Chemother 2014;69(2):568-571

130 Humphries RM, Pollett S, Sakoulas G. A current perspective on daptomycin for the clinical microbiologist. Clin Microbiol Rev 2013;26(4):759-780

131 Bayer AS, Schneider T, Sahl HG. Mechanisms of daptomycin resistance in Staphylococcus aureus: role of the cell membrane and cell wall. Ann N Y Acad Sci 2013;1277:139-158

132 Howden BP, McEvoy CR, Allen DL, et al. Evolution of multidrug resistance during Staphylococcus aureus infection involves mutation of the essential two component regulator WalKR. PLoS Pathog 2011;7(11):e1002359

133 Bertsche U, Yang SJ, Kuehner D, et al. Increased cell wall teichoic acid production and D-alanylation are common phenotypes among daptomycin-resistant methicillin-resistant Staphylococcus aureus (MRSA) clinical isolates. PLoS ONE 2013;8(6):e67398

134 Kelley PG, Gao W, Ward PB, Howden BP. Daptomycin nonsusceptibility in vancomycin-intermediate Staphylococcus aureus (VISA) and heterogeneous-VISA (hVISA): implications for therapy after vancomycin treatment failure. J Antimicrob Chemother 2011;66(5):1057-1060

135 van Hal SJ, Paterson DL, Gosbell IB. Emergence of daptomycin resistance following vancomycin-unresponsive Staphylococcus aureus bacteraemia in a daptomycin-naïve patient-a review of the literature. Eur J Clin Microbiol Infect Dis 2011;30(5):603-610 
136 Kollef MH, Rello J, Cammarata SK, Croos-Dabrera RV, Wunderink RG. Clinical cure and survival in Gram-positive ventilator-associated pneumonia: retrospective analysis of two double-blind studies comparing linezolid with vancomycin. Intensive Care Med 2004;30(3):388-394

137 Wunderink RG, Niederman MS, Kollef MH, et al. Linezolid in methicillin-resistant Staphylococcus aureus nosocomial pneumonia: a randomized, controlled study. Clin Infect Dis 2012; 54(5):621-629

138 Jiang H, Tang RN, Wang J. Linezolid versus vancomycin or teicoplanin for nosocomial pneumonia: meta-analysis of randomised controlled trials. Eur J Clin Microbiol Infect Dis 2013; 32(9):1121-1128

139 Kalil AC, Klompas M, Haynatzki G, Rupp ME. Treatment of hospital-acquired pneumonia with linezolid or vancomycin: a systematic review and meta-analysis. BMJ Open 2013;3(10): e003912

140 Kalil AC, Murthy MH, Hermsen ED, Neto FK, Sun J, Rupp ME. Linezolid versus vancomycin or teicoplanin for nosocomial pneumonia: a systematic review and meta-analysis. Crit Care Med 2010;38(9):1802-1808

141 Walkey AJ, O'Donnell MR, Wiener RS. Linezolid vs glycopeptide antibiotics for the treatment of suspected methicillin-resistant Staphylococcus aureus nosocomial pneumonia: a meta-analysis of randomized controlled trials. Chest 2011;139(5):1148-1155

142 Falagas ME, Manta KG, Ntziora F, Vardakas KZ. Linezolid for the treatment of patients with endocarditis: a systematic review of the published evidence. J Antimicrob Chemother 2006;58(2): 273-280

143 Schwalm JD, El-Helou P, Lee CH. Clinical outcome with oral linezolid and rifampin following recurrent methicillin-resistant Staphylococcus aureus bacteremia despite prolonged vancomycin treatment. Can J Infect Dis Med Microbiol 2004;15(2):97-100

144 Jang HC, Kim SH, Kim KH, et al. Salvage treatment for persistent methicillin-resistant Staphylococcus aureus bacteremia: efficacy of linezolid with or without carbapenem. Clin Infect Dis 2009; 49(3):395-401

145 Park HJ, Kim SH, Kim MJ, et al. Efficacy of linezolid-based salvage therapy compared with glycopeptide-based therapy in patients with persistent methicillin-resistant Staphylococcus aureus bacteremia. J Infect 2012;65(6):505-512

146 Fu J, Ye X, Chen C, Chen S. The efficacy and safety of linezolid and glycopeptides in the treatment of Staphylococcus aureus infections. PLOS ONE 2013;8(3):e58240

147 Shorr AF, Kunkel MJ, Kollef M. Linezolid versus vancomycin for Staphylococcus aureus bacteraemia: pooled analysis of randomized studies. J Antimicrob Chemother 2005;56(5):923-929

148 Locke JB, Zurenko GE, Shaw KJ, Bartizal K. Tedizolid for the management of human infections: in vitro characteristics. Clin Infect Dis 2014;58(Suppl 1):S35-S42

149 Shaw KJ, Barbachyn MR. The oxazolidinones: past, present, and future. Ann N Y Acad Sci 2011;1241:48-70

150 Rodríguez-Avial I, Culebras E, Betriu C, Morales G, Pena I, Picazo JJ. In vitro activity of tedizolid (TR-700) against linezolidresistant staphylococci. J Antimicrob Chemother 2012;67(1): 167-169

151 Thomson KS, Goering RV. Activity of tedizolid (TR-700) against well-characterized methicillin-resistant Staphylococcus aureus strains of diverse epidemiological origins. Antimicrob Agents Chemother 2013;57(6):2892-2895

152 Prokocimer P, De Anda C, Fang E, Mehra P, Das A. Tedizolid phosphate vs linezolid for treatment of acute bacterial skin and skin structure infections: the ESTABLISH-1 randomized trial. JAMA 2013;309(6):559-569

153 Das D, Tulkens PM, Mehra P, Fang E, Prokocimer P. Tedizolid phosphate for the management of acute bacterial skin and skin structure infections: safety summary. Clin Infect Dis 2014;58 (Suppl 1):S51-S57
154 Fuchs PC, Barry AL, Brown SD. Bactericidal activity of quinupristin-dalfopristin against Staphylococcus aureus: clindamycin susceptibility as a surrogate indicator. Antimicrob Agents Chemother 2000;44(10):2880-2882

155 Jones RN, Ballow CH, Biedenbach DJ, Deinhart JA, Schentag JJ. Antimicrobial activity of quinupristin-dalfopristin (RP 59500, Synercid) tested against over 28,000 recent clinical isolates from 200 medical centers in the United States and Canada. Diagn Microbiol Infect Dis 1998;31(3):437-451

156 Dowzicky M, Nadler HL, Feger C, Talbot G, Bompart F, Pease M. Evaluation of in vitro activity of quinupristin/dalfopristin and comparator antimicrobial agents against worldwide clinical trial and other laboratory isolates. Am J Med 1998;104(5A):34S-42S

157 Drew RH, Perfect JR, Srinath L, Kurkimilis E, Dowzicky M, Talbot GH. For the Synercid Emergency-Use Study Group. Treatment of methicillin-resistant staphylococcus aureus infections with quinupristin-dalfopristin in patients intolerant of or failing prior therapy. J Antimicrob Chemother 2000;46(5):775-784

158 Fagon J, Patrick H, Haas DW, et al; Nosocomial Pneumonia Group. Treatment of gram-positive nosocomial pneumonia. Prospective randomized comparison of quinupristin/dalfopristin versus vancomycin. Am J Respir Crit Care Med 2000;161(3 Pt 1):753-762

159 Berthaud N, Montay G, Conard BJ, Desnottes JF. Bactericidal activity and kinetics of RP 59500 in a mouse model of Staphylococcus aureus septicaemia. J Antimicrob Chemother 1995;36(2):365-373

160 Hamel A, Caillon J, Jacqueline C, Batard E, Potel G. Efficacy of quinupristin/dalfopristin versus vancomycin, alone or in combination with rifampicin, against methicillin-resistant Staphylococcus aureus in a rabbit arthritis model. Int J Antimicrob Agents 2008;31(2):158-160

161 Chambers HF. Studies of RP 59500 in vitro and in a rabbit model of aortic valve endocarditis caused by methicillin-resistant Staphylococcus aureus. J Antimicrob Chemother 1992;30(Suppl A ): $117-122$

162 Nichols RL, Graham DR, Barriere SL, et al; Synercid Skin and Skin Structure Infection Group. Treatment of hospitalized patients with complicated gram-positive skin and skin structure infections: two randomized, multicenter studies of quinupristin/dalfopristin versus cefazolin, oxacillin or vancomycin. J Antimicrob Chemother 1999;44(2):263-273

163 Wood MJ. The comparative efficacy and safety of teicoplanin and vancomycin. J Antimicrob Chemother 1996;37(2):209-222

164 Yahav D, Lador A, Paul M, Leibovici L. Efficacy and safety of tigecycline: a systematic review and meta-analysis. J Antimicrob Chemother 2011;66(9):1963-1971

165 Florescu I, Beuran M, Dimov R, et al; 307 Study Group. Efficacy and safety of tigecycline compared with vancomycin or linezolid for treatment of serious infections with methicillin-resistant Staphylococcus aureus or vancomycin-resistant enterococci: a Phase 3, multicenter, double-blind, randomized study. J Antimicrob Chemother 2008;62(Suppl 1):i17-i28

166 Mendes RE, Sader HS, Deshpande L, Jones RN. Antimicrobial activity of tigecycline against community-acquired methicillinresistant Staphylococcus aureus isolates recovered from North American medical centers. Diagn Microbiol Infect Dis 2008; 60(4):433-436

167 Goff DA, Dowzicky MJ. Prevalence and regional variation in meticillin-resistant Staphylococcus aureus (MRSA) in the USA and comparative in vitro activity of tigecycline, a glycylcycline antimicrobial. J Med Microbiol 2007;56(Pt 9):1189-1193

168 Kaya O, Akcam FZ, Temel EN. In vitro activities of linezolid and tigecycline against methicillin-resistant Staphylococcus aureus strains. Microb Drug Resist 2008;14(2):151-153

169 Denis O, Deplano A, Nonhoff C, et al. In vitro activities of ceftobiprole, tigecycline, daptomycin, and 19 other antimicrobials against methicillin-resistant Staphylococcus aureus strains from a national survey of Belgian hospitals. Antimicrob Agents Chemother 2006;50(8):2680-2685 
170 Antonopoulou A, Tsaganos T, Tzepi IM, Giamarellou H, Giamarellos-Bourboulis EJ. Comparative efficacy of tigecycline VERSUS vancomycin in an experimental model of soft tissue infection by methicillin-resistant Staphylococcus aureus producing PantonValentine leukocidin. J Chemother 2014:Y0000000171

171 Kandemir O, Oztuna V, Colak M, Akdag A, Camdeviren H. Comparison of the efficacy of tigecycline and teicoplanin in an experimental methicillin-resistant Staphylococcus aureus osteomyelitis model. J Chemother 2008;20(1):53-57

172 Matthews P, Alpert M, Rahav G, et al; Tigecycline 900 cSSSI Study Group. A randomized trial of tigecycline versus ampicillin-sulbactam or amoxicillin-clavulanate for the treatment of complicated skin and skin structure infections. BMC Infect Dis 2012; $12: 297$

173 Ramirez J, Dartois N, Gandjini H, Yan JL, Korth-Bradley J, McGovern PC. Randomized phase 2 trial to evaluate the clinical efficacy of two high-dosage tigecycline regimens versus imipenem-cilastatin for treatment of hospital-acquired pneumonia. Antimicrob Agents Chemother 2013;57(4):1756-1762

174 Tasina E, Haidich AB, Kokkali S, Arvanitidou M. Efficacy and safety of tigecycline for the treatment of infectious diseases: a metaanalysis. Lancet Infect Dis 2011;11(11):834-844
175 Prasad P, Sun J, Danner RL, Natanson C. Excess deaths associated with tigecycline after approval based on noninferiority trials. Clin Infect Dis 2012;54(12):1699-1709

176 Cai Y, Wang R, Liang B, Bai N, Liu Y. Systematic review and metaanalysis of the effectiveness and safety of tigecycline for treatment of infectious disease. Antimicrob Agents Chemother 2011; 55(3):1162-1172

177 McGovern PC, Wible M, El-Tahtawy A, Biswas P, Meyer RD. Allcause mortality imbalance in the tigecycline phase 3 and 4 clinical trials. Int J Antimicrob Agents 2013;41(5):463-467

178 Canut A, Isla A, Betriu C, Gascón AR. Pharmacokinetic-pharmacodynamic evaluation of daptomycin, tigecycline, and linezolid versus vancomycin for the treatment of MRSA infections in four western European countries. Eur J Clin Microbiol Infect Dis 2012;31(9):2227-2235

179 Giamarellou H, Poulakou G. Pharmacokinetic and pharmacodynamic evaluation of tigecycline. Expert Opin Drug Metab Toxicol 2011;7(11):1459-1470

180 Bhavnani SM, Rubino CM, Hammel JP, et al. Pharmacological and patient-specific response determinants in patients with hospitalacquired pneumonia treated with tigecycline. Antimicrob Agents Chemother 2012;56(2):1065-1072 